\title{
Socio-ecological Systems Analysis of the Prevention and Control of Dengue in two Districts of Dar es Salaam City, Tanzania
}

Leonard E.G. Mboera ( $\square$ Imboera@gmail.com )

Sokoine University of Agriculture https://orcid.org/0000-0001-5746-3776

Calvin Sindato

National Institute for Medical Research

Irene R. Mremi

National Institute for Medical Research

Susan F. Rumisha

National Institute for Medical Research

Janeth George

SACIDS Foundation for One Health

Renfrid Ngolongolo

SACIDS Foundation for One Health

Gerald Misinzo

Sokoine University of Agriculture

Esron D. Karimuribo

Sokoine University of Agriculture

Mark M. Rweyemamu

SACIDS Foundation for One Health

Najmul Haider

The Royal Veterinary College

Muzamil Abdel Hamid

University of Khartoum

Richard Kock

The Royal Veterinary College

\section{Research Article}

Keywords: Dengue, socio-ecological systems, readiness, surveillance, Tanzania

Posted Date: June 2nd, 2021

DOl: https://doi.org/10.21203/rs.3.rs-508043/v1 
License: (c) (i) This work is licensed under a Creative Commons Attribution 4.0 International License. Read Full License 


\section{Abstract}

Background: Since 2010, Tanzania has been experiencing frequent outbreaks of dengue. The objective of this study was to carry out a socio-ecological systems analysis and assess the readiness in dengue prevention and control in Kinondoni and Ilala districts of Dar es Salaam City, Tanzania.

Methods: Twenty-seven key district officials responsible for human and animal health were involved in a socio-ecological systems framework analysis as regards to dengue. In addition, the readiness of the districts to respond to dengue outbreaks and the performance of the disease surveillance system was assessed.

Results: The two districts were characterized by both urban and peri-urban ecosystems, with a mixture of planned and unplanned settlements which support breeding and proliferation of Aedes mosquitoes. The results indicate inadequate levels of readiness in the management and control of dengue outbreaks, in terms of clinical competence, diagnostic capacities, surveillance system and control/prevention measures. Mosquito breeding sites, especially discarded automobile tyres, were reported to be scattered in the districts. Constraining factors in implementing disease surveillance included both intrapersonal and interpersonal factors, lack of case management guidelines, difficult language used in standard case definitions, inadequate laboratory capacity, lack of appropriate rapid response teams, inadequate knowledge on outbreak investigation and inadequate capacities in data management.

Conclusion: The two districts had limited readiness in the management and control of dengue, in terms of clinical competence, diagnostic capacities, surveillance system and prevention and control measures. These challenges require the immediate attention by the authorities, as they compromise the effectiveness of the national strategy for community health support.

\section{Introduction}

Tanzania has experienced several outbreaks of mosquito-borne viral diseases (MBVDs) including dengue, chikungunya and Rift Valley fever over the last two decades [1-4]. These diseases are ecologically sensitive, since environmental conditions, such as temperature and precipitation, affect both the infectious pathogens and the vectors that transmit them [5-6]. MBVDs have received little attention, most likely due to inadequate knowledge, awareness and inadequate diagnostic capacity. The ecology and transmission of MBVDs are closely related to environmental resource management, social and behavioural patterns [7]. Thus, the mechanisms underlying MBVDs require exploring complex interactions within and among coupled natural and human systems, considering human and natural ecologies, and the multiple layers of interaction among them [8-10]. Usually, MBVD risk increases as a result of the effect of heavy rainfall providing habitat suitability for mosquito breeding opportunities $[5,11]$. Furthermore, repeated drought conditions and inadequate/unreliable water supply encourage storage of water for human and livestock consumption, the practices which provide the breeding sites for Aedes aegypti, the primary vector of dengue [12]. 
A better understanding of the relationship between development transitions and emerging and reemerging infectious diseases is critical for improving capability to predict and respond to epidemics. The complex nature of emerging and re-emerging infectious diseases highlights the need for new approaches to understand the mechanisms and processes underlying pathogen emergence to improve disease prevention and control. However, there are limited studies that have attempted to apply socio-ecological systems (SES) framework analysis on emerging and re-emerging infectious diseases in low-and middleincome countries [13]. It is important to understand how transformations in socio-ecological systems caused by multifaceted interactions between anthropogenic environmental changes such as urbanization, livelihoods activities, and natural habitat alterations, produce feedbacks that affect natural communities and ultimately their pathogens, animal and human populations [14-15].

The socio-ecological theory provides a framework for examining how individuals, their health, and their surrounding physical and social environments interact at multiple levels of a health problem and their interdependency $[5,16]$. The levels are: (i) Intrapersonal factors such as individual attitudes, behaviours, knowledge, and skills; (ii) Interpersonal processes and community factors, such as social networks made of family, friends, or colleagues that provide support; (iii) Institutional factors such as formal or informal organizations that may have rules or expectations that impact health behaviours; (iv) laws, policies or regulations that promote or inhibit certain health practices that impact disease management, control or prevention [17-20].

The development of a framework for analysing social-ecological models aims to understand how these systems function, and the processes through which they interact to influence disease outbreaks. To our knowledge, only a single study carried out in Tanzania has so far documented socio-ecological factors as regards to dengue epidemics [21]. Moreover, the readiness of national and sub-national levels in dengue and other mosquito-borne viral disease mitigations has not been assessed in Tanzania. Identifying community and district levels health determinant factors for dengue transmission will provide specific targets for public health interventions. The objectives of this study were to (i) carry out a socio-ecological systems analysis on dengue to identify risk factors and interventions at the district level; and (ii) assess the readiness of the district in the prevention and control of dengue.

\section{Methods}

\section{Study area}

This study was carried out during October 2019 and involved Ilala and Kinondoni districts of Dar es Salaam city in eastern Tanzania. The city with an area of $1,339 \mathrm{~km}^{2}$, is made up of five administrative districts, namely Ilala, Kigamboni, Kinondoni, Temeke and Ubungo. According to the 2012 national census, the city had a population of 4,364,541 (Ilala $=1,220,611$; Kinondoni $=1,775,049$ ), with an annual growth rate of 5.6\% [22]. The climate of Dar es Salaam is generally hot and humid with small seasonal and daily variations in temperature. The mean daily temperature is $26^{\circ} \mathrm{C}$, the mean seasonal range is $4^{\circ} \mathrm{C}$, and the mean daily range is about $8^{\circ} \mathrm{C}$. There are two rainy seasons, long (March-June) and short 
(October-December) with total annual rainfall averages $1,100 \mathrm{~mm}$. The relative humidity is generally high, reaching $100 \%$ almost every night throughout the year, but falling to $60 \%$ during the day [23-24].

Dar es Salaam has been facing continued dengue outbreaks with increased frequency and occurrence during the past 10 years. The occurrence of dengue outbreaks was reported in 2010, 2012, 2013, 2014, 2018 and 2019 [2, 3, 25-26]. During the 2019 outbreak, about 6,917 cases including 13 deaths were reported between January and July 2019 in Tanzania [27]. Two districts of Dar es Salaam, namely Kinondoni and llala were selected for this study because of their experience in dengue outbreaks since 2010 [2-3]. We hypothesized that following experience of several dengue outbreaks, the districts would have plans and built their capacities on outbreak preparedness and response.

\section{Data collection}

Key officials of the departments responsible for human and animal health of the Dar es Salaam city and Ilala and Kinondoni districts were invited to a SES framework analysis workshop. The workshop comprised of series of presentations, group exercises and plenary sessions. Presentations included general overview of MBVDs in Tanzania, SES framework analysis and principles and functions of public and animal health surveillance systems. The group working sessions focused on specific assignments on SES framework analysis on dengue. A mapping exercise was also carried out to analyse the performance of the disease surveillance system at district and facility levels.

\section{District SES framework analysis}

This exploratory study utilized a cross-sectional purposive selection of key stakeholders responsible for disease surveillance and response in human and animal populations. The stakeholders were brought together to foster interdisciplinary collaboration and stimulate transdisciplinary approaches to improve prevention and control of MBVDs. We applied SES framework [28-31] to identify drivers and construct perceived thematic causal explanations of the dengue outbreaks in the study districts. The SES approach allows the application of a variety of methodological process to study the field of interest [32]. Building on a conceptual framework developed by ecologists to address natural resource management issues [28-31], we adapted the steps to the interface of human and natural systems to assess the capacity of the districts in addressing MBVDs. Participants worked in two groups, each for the respective district. Group works were followed by group presentations and discussions.

District readiness to epidemics: A semi-structured questionnaire was used to assess and document the districts' clinical competence of healthcare providers, diagnostic capacity, surveillance and control interventions. The assessment of the surveillance system covered the following items: structures of the surveillance system, staff and resources, responsibility units and capacity to respond to infectious disease outbreaks. Disease surveillance, response and control programmes and networks were assessed to evaluate the capacity to detect, notify, assess and respond to known, new, and unknown infectious disease threats. The gaps were identified and solutions to enhance utilization of data for relevant sources 
for decision making process were proposed. Exploration was made to map how the districts were working and what actions would be needed to improve surveillance and response strategies in the districts.

\section{Data management and analysis}

We used data from the in-depth interviews to assess levels, practices and factors influencing socioecological system, epidemic readiness, disease surveillance capacity at health facility level and district level, and dengue prevention and control. Content analysis technique was applied using manifest surface structure approach [33] to group different expressions provided by participants into discrete categorical responses reflecting the specific themes defined by different variables in the SES framework analysis tool used. Data was summarized using a narrative structure for SES and were interpreted based on existing related literature, theories and knowledge/experience of the researchers.

\section{Results}

\section{Socio-ecological system analysis}

The workshop brought together 27 participants comprising of regional and district medical/ health officers, regional and district health management information systems officers, veterinary officers, information and communication technology specialists, surveillance officers and researchers. A number of observations and issues were raised as regards to the capacity of the country in addressing MBVDs. It was explained that until early 2000 s, the Ministry of Health had a department responsible for the coordination of all issues pertaining to vector-borne diseases. However, the department does not exist anymore; and the activities related to vector-borne diseases were being implemented separately through vertical programmes. Such programmes focused on specific diseases such as malaria, lymphatic filariasis, trachoma and onchocerciasis.

The two districts were characterized by both urban and peri-urban ecosystems, with mostly medium to high density human populations. A mixture of planned and unplanned settlements was common in both districts. Backyard poultry, pig and dairy farming was common in llala, but limited in Kinondoni district. Housing was characterized by iron roofing, with some of the houses having roof rain gutters. The main economic activities in Kinondoni included small-scale industries, business and extractive quarrying mining activities. In llala they included medium to large-scale food and non-food industries, business, fishing activities, crop production and extractive quarrying of sand. Seasonal cropping of vegetables and pot flower gardening were common practices in the two districts (Fig. 1). The sources of energy in both districts included electricity, charcoal, firewood, solar, gas and kerosene. Though solid waste management and disposal was centralized, improper household waste disposal was common in the two districts.

\section{Epidemic readiness}

Overall, none of the two districts reported adequate readiness in the management and control of dengue, both in terms of clinical competence, diagnostic capacities, surveillance and control/prevention 
measures. The challenges related to clinical competence included lack of standard case definition (SCD), standard operating procedures, inadequate rapid diagnostic tests, lack of case management guidelines, inadequate human resource and lack of job aids. The major challenges in surveillance were poor data quality (completeness and consistency), timeliness, inadequate data analysis capacity and unavailability of data sharing policy and practices. Community-based disease surveillance programme was not part of the surveillance system in the two districts. None of the districts had a contingency plan for dengue.

Treatment guidelines for dengue were available, but not disseminated widely at all levels in the districts (Table 1). 
District readiness in the management and control of dengue

Variable llala Kinondoni

Clinical competence of healthcare providers

- Standard case definition

Not available

Available but not used

- Case management guidelines

Not available

Not available

- Human resource availability

Inadequate

Inadequate

Diagnostic capacity

- Availability of rapid diagnostic test

Inadequate

Inadequate

-Availability of other related diagnostic test (FBP,

Inadequate

Inadequate

ESR, Platelets)

- Availability of guidelines/standard operation procedures/job aids

Not available

Not available

Surveillance system in place and functional

- Data quality (completeness, consistency)

Some data quality

Poor

- Data analytical capacity (pattern, demographic, hot spots identified from surveillance data)

- Data sharing policy and practices

Inadequate capacity Weak

Not in place

Not in place

Control interventions available

- Contingency plan available

None

None

- Community involvement

None

None

- Health education and promotion

Limited

Limited

- Source reduction programme

None

None

- Vector control

Larviciding as

malaria vector

intervention

Larviciding as

malaria vector

intervention

- Insecticide-treated mosquito net

High coverage

High coverage

Partners collaborators

Not available

Not available

Key: $\mathrm{FBP}=$ full blood picture; ESR= erythrocyte sedimentation rate

\section{Disease surveillance}

Facility level. At the facility level (which include district hospital, health centre and dispensary), participants from Kinondoni identified availability of forms for reporting and routine meetings with local 
authorities as the only facilitating factors in implementing surveillance programme. The constraining factors reported included lack of guidelines, dissemination and translation of SCDs (which were in English) and low diagnostic capacities for dengue. Lack of smooth communication network and appropriate rapid response team were reported. Low capacity on data management, including analysis, was reported to negatively affect the decision-making process at health facility level. Inadequate knowledge on outbreak investigation among health facility workers and shortage of sample collection equipment were identified as critical gaps. In Ilala, although the SCD were available, most of the clinicians reported to have not received orientation on their use. Data analysis and interpretation at health facility level was not been done properly due to inadequate knowledge and skills. Like in Kinondoni, the participants reported that facility level health care workers were not part of the outbreak investigation team.

\section{District level}

In Kinondoni the identified constraining factors were (i) lack of data collection tools, shortage of staff and insufficient laboratory reagents; (ii) external and internal transfer of trained staff; insufficient knowledge and unreliable internet connectivity; (iii) inadequate communication tools; (iv) delays in receiving reports from the facilities or community levels; (vi) lack of periodic supportive supervision from higher levels; (vi) low capacity of the district outbreak response team; and (vii) inadequate budget for surveillance activities.

In llala, participants reported on lack of feedback on data analysis as the most critical challenge in the use of surveillance data. They were not able to compare current and previous pattern (trends) of the disease due to poor quality data. Unavailability of sample collection tools and unclear responsibilities for health care workers were underscored as the key limiting factors in the outbreak investigation. It was pointed out that although the district took part in disease outbreak response, its staff lacked training on emergency preparedness and responses due to inadequate budget. They also reported that an Epidemic Response Committee in the district was not functioning. Most of the guidelines were reported to be in English, voluminous and not handy. The guidelines were perceived by most participants to be difficult to follow. It was proposed that the guidelines be translated into Kiswahili (the national language) and made available in simple user-friendly formats.

In the two districts, analysis tools for surveillance data were not in place. Moreover, it was reported that the surveillance officers were not skilled enough on data management especially, analysis and interpretation. There were a number of health information systems for district and facility to use. They included Health Management Information System (HMIS), National System for Government Health Officials, Government of Tanzania Hospital Management Information System and others. All these were described to bring confusion to health workers. There was no information, knowledge, skills and experience sharing practices on data management between surveillance and HMIS officers at the district level. 


\section{Dengue prevention and control}

During the discussion, an issue on unchecked mosquito breeding sites in Dar es Salaam city was raised and discussed. Mosquito breeding sites especially discarded automobile tyres were reported to be scattered and found in almost all areas of the city. The automobile tyres were described to contribute to over two-thirds of the breeding sites for Aedes mosquitoes. Participants were concerned with the lack of appropriate actions as regards to disposal of discarded automobile tyres and water-carrying containers. It was reported that in the old days, the destruction of used automobile tyres was done by burning. However, the programme failed, as it required burning chambers, which were not available. It was noted that although a malaria larviciding programme was been implemented in the city, it was not appropriately executed; and was perceived to be ineffective against Aedes mosquitoes. Participants noted that the malaria mosquito larviciding project focused on large water bodies and left small water bodies and containers unchecked. Moreover, the programme was being implemented in only $60 \%$ of the wards. The participants raised their concerns for the districts inadequate budget for outbreaks response. The low level of awareness on dengue and Rift Valley fever was reported for both districts (Fig. 2).

The following were proposed as the way forward in addressing the challenges in the control of dengue: (i) revising the larviciding programme to cover much larger areas of the city and target the priority mosquitoborne disease vectors; (ii) enhancing capacity in dengue diagnosis and case management; and (iii) developing a strategic plan to address advocacy to the regional and district government authorities as regards to the importance of outbreak preparedness.

\section{Discussion}

Dengue has become an increasingly important public health problem in the tropical world in terms of morbidity and mortality. With rapidly changing human population and activities, the ecology of both the pathogens and vectors, climate variability/change coupled with weak health systems, dengue outbreaks are likely to become more frequent. In our approach, we addressed the reality that effective prevention and control of dengue cannot be achieved from narrow perspectives, but would largely benefit from a holistic approach that considers an improved understanding of SES and health system readiness. The basic idea of SES is to be explicit in system thinking and linking together the 'human system' and the 'natural system' in a two-way feedback relationship.

The interactions between humans, pathogens and environment, suggest that SES is crucial in disease occurrence and transmission dynamics. Moreover, the readiness of national and sub-national levels in dengue mitigations is central in the designing and planning of appropriate intervention measures. It is against this background that we conducted this analysis to identify socioecological factors and readiness of the districts in the control and prevention of dengue. In our data collection process, we adopted a consultative workshop method, which has been found to foster engagement through collaborative discussions and constructive feedback between participants from different organizations and facilitators on a particular topic [34-35]. The approach helped us to obtain information-rich data and 
persistent observation on dengue management and control in the study districts from purposively selected key stakeholders, which is similar to a consideration reported elsewhere [36].

In the SES framework analysis, we found that the ecological descriptors of Ilala and Kinondoni were characterised by both urban and peri-urban ecosystems with planned and unplanned settlements. Although in our study we did not establish the impact of urbanization on the occurrence of dengue, urban and peri-urban areas have been reported to be vulnerable to the disease, the outcome which is driven by rapid and uncontrolled urbanization that support Aedes mosquito productivity [2,37-38]. The intrapersonal factors such as in-house water storage, improper household waste water disposal were common practices in the districts. The presence of potential mosquito breeding sites including discarded automobile car tyres, flower pots and water stagnation were reported to support habitat suitability for mosquito breeding and thereby increasing the risk of occurrence of dengue in the two districts $[2,21]$.

It was reported that to date, there have been no effective measures in the disposal of used automobile tyres. As a result, they were improperly discarded and continued to stockpile in the districts. Tyre stockpiles create a great health risk as they provide permissive breeding grounds for mosquitoes [39]. Used automobile tyres and domestic water storage containers have been reported as the most important larval habitats for Ae. aegypti in Dar es Salaam and Zanzibar [40-41]. These observations suggest that the solution to proper management of mosquito breeding sites does not fall clearly within the boundaries of a single discipline or sector but rather a multi-sectoral approach.

Vulnerability to dengue was considered disproportionately distributed within each of the study districts. This suggests that interventions to address them should be repackaged based on specific-area risk profiles. However, as we have highlighted on the inefficiency of surveillance systems based on districtlevel SES framework analysis, we cannot account explicitly on the representation of vulnerability of subdistrict levels to dengue. SES framework analysis at the sub-district levels is likely to complement our understanding on the vulnerability profiles at different ecological levels.

One of the strategic mosquito prevention measures in the districts was larviciding. However, in the two districts, larviciding, which was introduced for malaria control [42], was implemented without consideration of the evidence to guide appropriate timing, areas and potential breeding sites of focus. We suggest that in order to effectively prevent dengue, it is important to implement the integrated vector management measures. This should be implemented by targeting the most suitable mosquito habitats to suppress mosquito larval stages thereby reducing adult emergence. Although larviciding has been recommended as a complementary intervention to control malaria [43], we suggest to conduct monitoring and evaluation of such interventions against the Aedes mosquitoes.

It has been established that indices of mosquito and climate factors are the main determinants of dengue [44-46]. Since microclimate dynamics is largely determined by human activities it is imperative to suggest that a key strategy to prevent and control dengue is to focus on addressing the anthropogenic factors. A number of ecological, biological and social factors are involved in mosquito breeding and pathogen transmission [47]. A study in Sri Lanka revealed that dengue outbreaks were significantly 
associated with ecological, socio-economic and demographic factors; including the presence of built-up area, and areas with higher human population density [48]. Existing evidence on the complexity of ecobio-social contexts repeatedly argues that dengue control necessitates sound intersectoral approaches that combine environmental management practices with community mobilization [49-51]. Probably intensification of public health education on proper management of water storage containers, discarded car tyres, periodic draining or removal of artificial containers could be the most effective strategy of reducing mosquito breeding habitats. Based on SES framework analysis results, we hypothesise that interventions on the management of potential mosquito breeding sites in domestic and peri-domestic environments and ecological health could generate data to guide sustainable community-based prevention strategies against dengue and other Aedes-borne viral diseases.

On assessing the capacity in responding to outbreaks, none of the two districts reported the readiness in the management of dengue outbreak. The availability of disease surveillance and management guidelines in English language was reported as a utilization impediment and participants proposed that they should be translated into Kiswahili. In our study, the guidelines were reported to be voluminous and not user-friendly. Since a number of guidelines continue to proliferate on the same or similar subjects, it is likely impractical for the practitioners to use them efficiently. The successful implementation of guidelines depends on many factors including participatory development, dissemination and implementation strategy as well as evaluation of their effectiveness [52]. The presence of guidelines may not guarantee their implementation or utility, and some studies have reported failure of guidelines to influence the implementation of health programmes [53-55]. The reasons that have been associated with failure of guidelines to achieve their objectives, include inadequate consultation, lack of consideration of technical capacity, attitude and behaviour of health professionals and lack of training on the use of the guidelines [56-58]. Adoption of a web- or mobile-based electronic platform to enhance, on the one hand data collection especially at community level and on the other, prompt searching by topic of interest or based on prevailing needs is likely to be a breakthrough. We believe that with increasing occurrence of infectious disease epidemics the efficiency of disease surveillance, early detection and early warning will require use of such web or mobile technologies [59]. This can be enhanced through application of machine learning data-mining integration with socio-ecological and geospatial analyses [60], specifically designed for low- and middle- income countries like Tanzania.

The capacities of the districts in dengue epidemic readiness was limited, and this calls for concerted efforts to improve resource availability, and training. Measuring readiness in epidemic preparedness and response is likely to present some challenges. This is because in this study epidemic preparedness focused mainly on human resource, infrastructure, and surveillance. The study did not document the relevant processes in epidemic preparedness or the activities executed during an epidemic response, including isolation and quarantine, public communication, and others [61].

Generally, the overall performance of the surveillance system in the two districts was not satisfactory in detecting and or monitoring trends of dengue. We recorded inadequate skills and capacity in outbreak investigation, insufficient laboratory supplies, poor surveillance data quality, inadequate data

Page $12 / 21$ 
management including data analysis, interpretation and use, and poor information/data sharing practices between sectors. The surveillance systems were reported to be inefficient with inadequate involvement of community and therefore not tailored for early detection and response. Limited or no evidence of routine data analysis at sub-national levels mainly due to lack of clear guidelines on how and when to analyse data has been reported in previous studies [62-65]. It has been described that when the health facilities do not analyse and use the data, the utility of the surveillance system becomes minimal, which makes the system too weak to pick outbreaks early that could guide prompt response. The absence of data analysis, interpretation and utilization for local action seen in the present study is in line with findings of studies in Ethiopia and Nigeria [66-68]. Skill gap in data management system, weak supervision and feedback system, low or no legal enforcement to the surveillance activities, lack of incentives, lack of continued capacity building training, and lack of sense of ownership have been reported as factors affecting analysis and use of surveillance data [66].

\section{Conclusions}

Using the SES framework analysis, through a consultative workshop data collection approach, we have managed to identify important features, the processes and assess the functioning of multifaceted and complex systems involved in management of dengue in the two districts of Tanzania. The findings illustrate that the districts have limited readiness in the management and control of dengue outbreaks. The surveillance system is faced by lack of or inappropriate format of guidelines, dissemination and translation for use of SCDs and insufficient reagents for laboratory confirmation of cases. Low capacity in data management, analysis and use was common in both districts. Inadequate knowledge on outbreak investigation among facility workers and shortage of sample collection and processing tools were identified as critical gaps. Individual and community practices and behaviours contribute to the challenges towards response to dengue outbreaks. The capacities of the districts in dengue epidemic readiness is limited. To strengthen epidemic preparedness at the district level, a well-functioning supervised surveillance system, with appropriate systems of analysis and feedback covering critical variables, is essential.

\section{Abbreviations}

ESR= Erythrocyte sedimentation rate; $\mathrm{FBP}=$ Full blood picture; HMIS= Health Management Information System; $L L I N=$ Long lasting insecticide nets; $M B V D=$ Mosquito-borne viral diseases; $S C D=$ Standard case definition; SES= Socio-ecological system

\section{Declarations}

\section{Acknowledgements}

We would like to thank the Dar es Salaam City Council, Ilala and Kinondoni Municipal Councils for their enthusiasm and support to the accomplishment of this study. 


\section{Authors' contributions}

LEGM, CS contributed to the study design. IRM, JG, RN, gathered the data and SFR, CS, JG and LEGM analysed the data. $\mathrm{NH}, \mathrm{MM}, \mathrm{RK}, \mathrm{MMR}, \mathrm{GM}$ and EDK contributed to drafting of the manuscript. All authors read and approved the final version of the manuscript.

\section{Funding}

This study received financial support from the European and Developing Countries Clinical Trials Partnership (EDCTP2) Programme (Grant RIA2016E-1609) which is supported under Horizon 2020, the European Union's Framework Programme for Research and Innovation.

\section{Availability of supporting data}

All data sets on which the findings and conclusions of this study rely are presented in the paper. However, data is available from the corresponding author upon reasonable request.

\section{Ethics approval and consent to participate}

This project received ethical approval by the Medical Research Coordinating Committee of the National Institute for Medical Research (Ref. NIMR/HQ/R.8c/Vol 1/1168).

\section{Consent for publication}

Not applicable

\section{Competing interests}

The authors declare that they have no competing interests

\section{References}

1. Sindato C, Karimuribo ED, Pfeiffer DU, Mboera, LEG, Kivaria, F, et al. Spatial and Temporal Pattern of Rift Valley Fever Outbreaks in Tanzania; 1930 to 2007. PLoS ONE. 2014; 9(2): e88897.

2. Mboera LEG, Mweya CN, Rumisha SF, Tungu PK, Stanley G, et al. The risk of dengue virus transmission in Dar es Salaam, Tanzania during an epidemic period of 2014. PLoS Negl Trop Dis. 2016; 10(1): e004313. doi: 10.1371/journal.pntd.0004313. 
3. Vairo F, Mboera LEG, De Nardo P, Oriyo NM, Meschi S, Rumisha SF, et al. Clinical, virologic, and epidemiologic characteristics of dengue outbreak, Dar es Salaam, Tanzania, 2014. Emerg Infect Dis. 2016; 22 (5): 895-899. doi: 3201/eid2205.151462.

4. Kinimi E, Shayo M, Bisimwa P, Angwenyi S, Kasanga C, Weyer J. et al. Evidence of chikungunya virus infection among febrile patients seeking healthcare in selected districts of Tanzania. Infect Ecol Epidemiol. 2018; 8: https://doi.org/10.1080/20008686.2018.1553460.

5. Cao Z, Liu T, Li X, Wang J, Lin H, Chen L, et al. Individual and interactive effects of socio-ecological factors on dengue fever at fine spatial scale: a geographical detector-based analysis. Int $\mathrm{J}$ of Environ Res Public Health. 2017; 14; 795. doi: 10.3390/ijerph14070795.

6. Thomson MC, Muñoz ÁG, Cousin, R, Shumake-Guillemot J. Climate drivers of vector-borne diseases in Africa and their relevance to control programmes. Infect Dis Poverty. 2018; 7: https://doi.org/10.1186/s40249-018-0460-1

7. Parham PE, Waldock J, Christophides GK, Hemming D, Agusto F, Evans KJ et al. Climate, environmental and socio-economic change: weighing up the balance in vector-borne disease transmission. Philos Trans Royal Soc B. 2015; 370 (1665): http://dx.doi.org/10.1098/rstb.2013.0551.

8. Berkes F, Colding J, Folke C. Navigating Social-Ecological Systems: Building Resilience for Complexity and Change. New York: Cambridge University Press. 2003.

9. Walker B, Holling CS, Carpenter SR, Kinzig A. Resilience, adaptability and transformability in socialecological systems. Ecol Soc. 2004; 9:5.

10. Liu J, Dietz T, Carpenter SR, Alberti M, Folke C, Moran E et al. Complexity of coupled human and natural systems. Science. 2007; 317:1513-1516. doi:10.1126/science.1144004.

11. Gerdes GH. Rift Valley fever. Rev Sci Tech. 2004; 23 (2):613-623. doi: 10.20506/rst.23.2.1500.

12. Powell JR, Tabachnick WJ. History of domestication and spread of Aedes aegypti - a review. Mem Inst Oswaldo Cruz. 2013; 108:11-17. doi: 1590/0074-0276130395.

13. Smith KR, Ezzati M. How environmental health risks change with development: The epidemiologic and environmental risk transitions revisited. Ann Rev Environ Res. 2005; 30: 291-333. https://doi.org/10.1146/annurev.energy.30.050504.144424.

14. Wilcox BA, Colwell RR. Emerging and re-emerging infectious diseases: biocomplexity as an interdisciplinary paradigm. EcoHealth 2005; 2(4): 244-257. https://doi.org/10.1007/s10393-0058961-3.

15. Wilcox BA, Gubler DJ. Disease ecology and the global emergence of zoonotic pathogens. Environ Health Prev Med 2005; 10(5): 263-272. doi: 1007/bf02897701.

16. McLaren L, Hawe P. (2005) Ecological perspectives in health research. J Epidemiol Comm Health 2005; 59(1):6-14. doi: 1136/jech.2003.018044.

17. McLeroy K, Bibeau D, Steckler A, Glanz K. An ecological perspective on health promotion programs. Health Edu Behav. 1988; 15(4): 351-377. https://doi.org/10.1177/109019818801500401. 
18. Gregson J, Foerster S, Orr R, Jones L, Benedict J, Clarke B, et al. (2001) System, environmental, and policy changes: Using the social-ecological model as a framework for evaluating nutrition education and social marketing programs with low-income audiences. J Nutr Educ Behav. 2001; 33: 4-15. doi: 10.1016/s1499-4046(06)60065-1.

19. Robinson T. Applying the socio-ecological model to improving fruit and vegetable intake among lowincome African Americans. J Comm Health. 2008; 33: 395-406. doi: 10.1007/s10900-008-9109-5.

20. Aguirre AA, Basu N, Kahn LH, Morin XK, Echaubard P, Wilcox BA. et al. Transdisciplinary and socialecological health frameworks-Novel approaches to emerging parasitic and vector-borne diseases. Parasite Epidemiol Control. 2019; 4: e00084. doi: 1016/j.parepi.2019.e00084.

21. Camara N, Ngasala B, Leyna G, Abade A, Rumisha SF, Oriyo NM. et al. Socio-demographic determinants of dengue infection during an outbreak in Dar es Salaam City, Tanzania. Tanzania J Health Res. 2018; 20(2). doi: http://dx.doi.org/10.4314/thrb.v20i2.3.

22. Population and Housing Census 2012. United Republic of Tanzania, Dar es Salaam, 2013.

23. Trpis M. Seasonal changes in the larval populations of Aedes aegypti in two biotypes in Dar es Salaam, Tanzania. Bull World Health Org. 1972; 47: 245-255.

24. Trpis M. Dry season survival of Aedes aegypti eggs in various breeding sites in the Dar es Salaam area, Tanzania. Bull World Health Org. 1972; 47(3): 433-437.

25. Vairo F, Nicastri E, Yussuf SM, Cannas A. et al. IgG against dengue virus in healthy blood donors, Zanzibar, Tanzania. Emerg Infect Dis, 2014; 20: 465-468. doi: 3201/eid2003.130150.

26. Okada K, Morita R, Egawa K, Hirai Y, Kaida A, Shirano M. Dengue virus type 1 infection in traveller returning from Tanzania to Japan, 2019. Emerg Infect Dis. 2019; 25(9):1782-1784. doi: 3201/eid2509.190814.

27. World Health Organization. Weekly Bulletin on Outbreaks and other emergencies. Week 31-47: 29 July-24 November 2019.

28. Ostrom E. A diagnostic approach for going beyond panaceas. Proc Natl Acad Sci USA. 2007; 104(39):15181-15187. http://dx.d org/10.1073/pnas.0702288104.

29. Ostrom E. A general framework for analyzing sustainability of social-ecological systems. Science 2009; 325 (5939): 419-422. http://dx.doi.org/10.1126/science.1172133.

30. Poteete A, Janssen MA, Ostrom E. Working together: collective action, the commons and multiple methods in practice. Princeton University Press, Princeton, New Jersey, USA 2002. http://dx.doi.org/10.1515/9781400835157.

31. McGinnis MD, Ostrom E. Social-ecological system framework: initial changes and continuing challenges. Ecol Soc. 2014; 19(2): 30. http://dx.doi.org/10.5751/ES-06387-190230.

32. Partelow S. Key steps for operationalizing social-ecological system framework research in smallscale fisheries: A heuristic conceptual approach. Mar Policy. 2015; 51(C): 507-511. doi: 10.1016/j.marpol.2014.09.005. 
33. Bengtsson, M. How to plan and perform a qualitative study using content analysis. Nurs Open. 2016; 8(2): 8-14. doi: 10.1016/j.npls.2016.01.001.

34. Sharma RC, Thakur A, Sharma M, Mishra S. Teachers' Perception of Open Educational Resources: Data Collection through Workshops (ROER4D). Paper presented at the Open Education Global Conference 2015. Calgary, AB. 2015.

35. Ørngreen R, Levinsen K. Workshops as a Research Methodology. EJEL. 2017; 15 (1): 70-81.

36. Lain S. Show, Don't Tell: Reading Workshop Fosters Engagement and Success. TJLE. 2017; 5(2): 160167.

37. Knudsen AB, Slooff R. Vector-borne disease problems in rapid urbanization: new approaches to vector control. Bull World Health Organ. 1992; 70:1-6.

38. Kendall C, Hudelson P, Leontsini E, Winch P, Lloyd L. Urbanization, dengue, and the health transition: Anthropological contributions to international health. Med Anthropol Q. 1993; 5:257-268. doi: 1525/maq.1991.5.3.02a00050.

39. Rubio A, Cardo V, Vezzani D. Tire-breeding mosquitoes of public health importance along an urbanisation gradient in Buenos Aires, Argentina. Mem Inst Oswaldo Cruz. 2011; 16(6): 678-684. doi: 1590/s0074-02762011000600006.

40. Philbert A, ljumba JN. Preferred breeding habitats of Aedes aegypti (Diptera- Culicidae) mosquito and its public health implications in Dar es Salaam, Tanzania. J Environ Res Manage. 2013; 4:344351.

41. Mathias L, Baraka V, Philbert A, Innocent E, Francis F, Nkwengulila G, Kweka EJ. Habitat productivity and pyrethroid susceptibility status of Aedes aegyptimosquitoes in Dar es Salaam, Tanzania. Infect Dis Poverty. 2017; 6:1-10. https://doi.org/10.1186/s40249-017-0316-0.

42. Saleh F, Kitau J, Konradsen F, Alifrangis M, Lin C, Juma S et al. Habitat characteristics for immature stages of Aedes aegyptiin Zanzibar City, Tanzania. J Am Mosq Control Assoc. 2018; 18 (34): 190200. doi: 2987/17-6709.1.

43. Maheu-Giroux M, Castro MC. Impact of Community-Based Larviciding on the Prevalence of Malaria Infection in Dar es Salaam, Tanzania. PLoS ONE 2013; 8(8): e71638. https://doi.org/10.1371/journal.pone.0071638.

44. World Health Organization. Larval source management: a supplementary measure for malaria vector control. Geneva, Switzerland, 2013.

45. Hales $S$, Weinstein P, Souares $Y$, Woodward A. El Nino and the dynamics of vector-borne disease transmission. Environ Health Perspect. 1999; 107(2): 99-102. doi: 1289/ehp.9910799.

46. Pham HV,Huong, Doan HTM, Phan TTT, Minh NNT. Ecological factors associated with dengue fever in a central highlands Province, Vietnam. BMC Infect Dis. 2011;11: 172. https://doi.org/10.1186/1471-2334-11-172.

47. Arunachalam N, Tana S, Espino F, Kittayapong P, Abeyewickreme W, Wai KT. et al. Eco-bio-social determinants of dengue vector breeding: a multicountry study in urban and periurban Asia. Bull World Health Organ. 2010; 88(3):173-184. 
48. Ault SK. Environmental management: a re-emerging vector control strategy. Am J Trop Med Hyg. 1994; 50:35-49. doi: 10.4269/ajtmh.1994.50.35.

49. Anno S, Imaoka K, Tadono T, Igarashi T, Sivaganesh S, Kannathasan S. et al. Space-time clustering characteristics of dengue based on ecological, socio-economic, and demographic factors in northern Sri Lanka. Geosp Health 2015; 10(376):215-222. doi: 4081/gh.2015.376.

50. Gubler DJ, Clark GG. Community involvement in the control of Aedes aegypti. Acta Trop. 1996; 61:169-179. doi: 10.1016/0001-706x (95)00103-I.

51. Parks W, Lloyd L. Planning Social Mobilization and Communication for Dengue Fever Prevention and Control a Step-by-step Guide. Geneva: World Health Organization, 2004.

52. Grimshaw JM, Russell IT. Effect of clinical guidelines on medical practice: a systematic review of rigorous evaluations. Lancet 1993; 342:1317-1322. doi: 10.1016/0140-6736(93)92244-n.

53. Nathwani D, Rubinstein E, Barlow G, Davey P. Do guidelines for community-acquired pneumonia improve the cost-effectiveness of hospital care? Clin Infect Dis. 2001; 32 (5):728-741. https://doi.org/10.1086/319216.

54. Grol R, Grimshaw J. From best evidence to best practice: effective implementation of change in patients' care. Lancet 2003; 362(9391):1225-1230. doi: 10.1016/S0140-6736(03)14546-1.

55. Gagliardi AR, Brouwers MC, Palda VA, Lemieux-Charles L, Grimshaw JM. How can we improve guideline use? A conceptual framework of implementability. Implement Sci. 2011; 6:26. https://doi.org/10.1186/1748-5908-6-2.6.

56. Armstrong PW. Do guidelines influence practice? Heart 2003; 89(3): 349-352.

57. Schunemann HJ, Fretheim A, Oxman AD. Improving the use of research evidence in guideline development: 1. Guidelines for guidelines. Health Res Policy Syst. 2006; 4:13. doi: 1186/1478-45054-13.

58. Stanback J, Griffey S, Lynam P, Ruto C, Cummings S. Improving adherence to family planning guidelines in Kenya: an experiment. Int J Qual Health Care 2007; 19(2):68-73. doi: 10.1093/intqhc/mzl072.

59. Francke AL, Smit MC, de Veer AJ, Mistiaen P. Factors influencing the implementation of clinical guidelines for health care professionals: a systematic meta-review. BMC Med Inform Dec. 2008; 8:38. https://doi.org/10.1186/1472-6947-8-38.

60. Karimuribo ED, Mutagahywa E, Sindato C, Mboera L, Mwabukusi M, Kariuki Njenga M. et al. A Smartphone App (AfyaData) for Innovative One Health Disease Surveillance from Community to National Levels in Africa: Intervention in Disease Surveillance. JMIR Public Health Surv. 2017; 3 (4): e94. doi: 10.2196/publichealth.7373.

61. Anno S, Hara T, Kai H, Chang Y, Lee M-A, Oyoshi K. et al. Deep learning applications for predicting Dengue fever outbreak. J Environ Res. 2018; 2: 21.

62. Nelson, C., Lurie, N. \& Wasserman, J. Assessing public health emergency preparedness: concepts, tools, and challenges. Annu Rev Public Health 2008; 28: 1-18. pmid:17129174. doi: 10.1146/annurev.publhealth.28.021406.144054. 
63. Mghamba JM, Mboera LEG, Krekamoo W, Senkoro KP, Rumisha SF, Shayo E. et al. Challenges of implementing an Integrated Disease Surveillance and Response strategy using the current Health Management Information System in Tanzania. Tanzania Health Res Bull. 2004; 6: 57-63. https://doi.org/10.4314/thrb.v6i2.14243.

64. Phalkey RK, Yamamoto S, Awate P, Marx Challenges with the implementation of an Integrated Disease Surveillance and Response (IDSR) system: systematic review of the lessons learned. Health Policy Plann. 2015; 30 (1): 131-143. doi: 10.1093/heapol/czt097.

65. Rumisha SF, Mboera LE, Senkoro KP, Gueye D, Mmbuji PK. Monitoring and evaluation of integrated disease surveillance and response in selected districts in Tanzania. Tanzania Health Res Bull. 2007; 9: 1-11. https://doi.org/10.4314/thrb.v9i1.14285.

66. Alemu T, Gutema H, Legesse S, Nigussie T, Yenew Y, Gahse K. Evaluation of public health surveillance system performance in Dangila district, Northwest Ethiopia: a concurrent embedded mixed quantitative/qualitative facility-based cross-sectional study. BMC Public Health 2019; 19 : https://doi.org/10.1186/s12889-019-7724-y.

67. Begashaw B, Tesfaye T. Assessment of integrated disease surveillance and response implementation in special health facilities of Dawuro Zone. J Anesthesiol. 2016; 4(3):11-15. doi: 11648/j.ja.20160403.11

68. Motilewa O, Akwaowo CD, Ekanem, AM. Assessment of implementation of integrated disease surveillance and response in Akwaibom State Nigeria. Ibom Med J. 2015; 8(1):24-25.

\section{Figures}




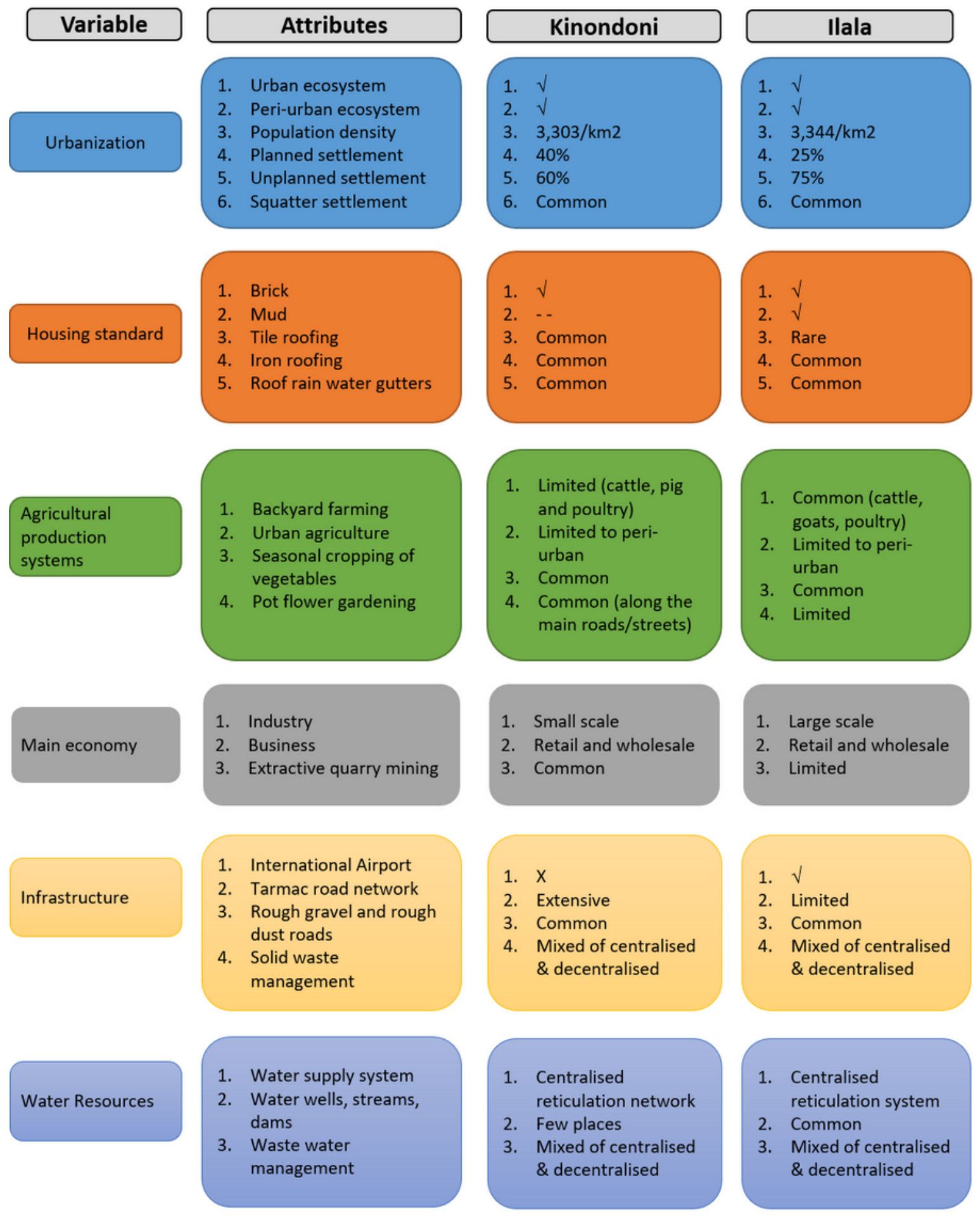

Key: $\sqrt{ }=$ mentioned with no quantification; " - " = Not mentioned; $X$ = Not available

\section{Figure 1}

District profiles and socio-ecological factors 


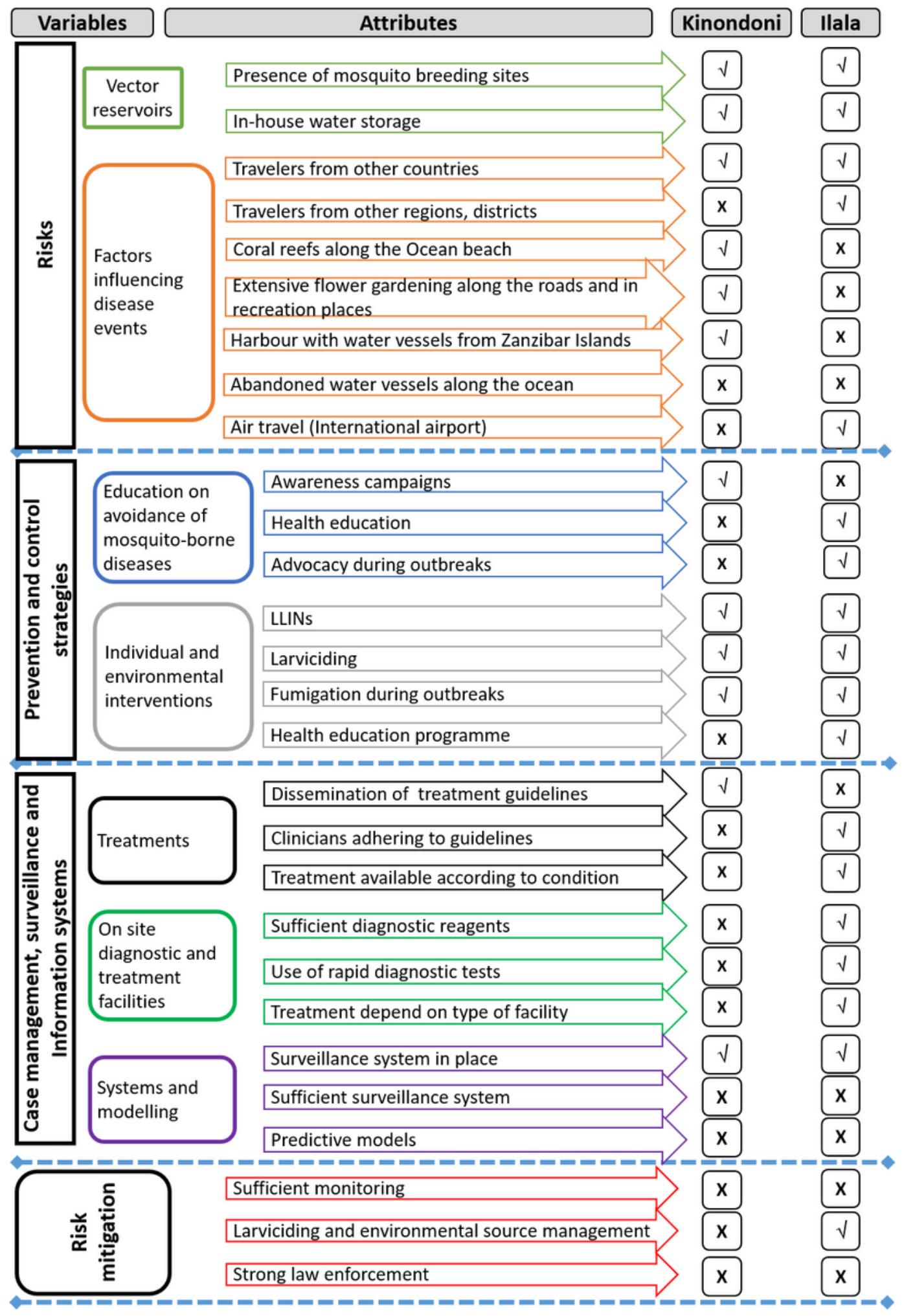

Figure 2

Presence $(\sqrt{ })$ and absence $(X)$ of risks, prevention and control activities for dengue in the study districts 